\title{
8. Body-Space-Relation in Parkour: Street Practices and Visual Representations
}

\author{
Ines Braune
}

\begin{abstract}
Parkour today is a global subcultural scene that combines street with media practices. Parkour consists of a local moment, fundamentally concerned with the materiality of the street, and simultaneously of a global digital discourse, which involves millions of parkour actors. While the spatial knowledge requires a very close knowledge and tactile contact of the surface's nature of space, the media representations seem to reflect an opposite image, namely the detachedness of space. In this chapter, I will address the question of space-making and spatial practices in Morocco and the relation to parkour's visual representations.
\end{abstract}

Keywords: Morocco, parkour, body, street

Today, parkour is a global cultural scene that combines the street with media practices. In that sense, parkour consists of a local moment, fundamentally concerned with the materiality of the street, and simultaneously of a global digital discourse involving millions of parkour actors, called traceurs, negotiating and re-evaluating their navigation through both physical and digital space.

The first and often only contact with parkour, from the point of view of non-practitioners, frequently comes through its visual representations. Spectacular images and videos depict the weightlessness of the body and its detachment from space. Scholars have also weighed in here, analysing the relationship between the body and public space - that is, the interaction and engagement between body and space - while also evaluating parkour as an online culture, assessing the relevance of (digital) media practices within parkour and other youth and sport cultures such as skateboarding (Borden 2001; Buckingham 2009) and surfing (Booth 1996; 2001).

Strohmaier, A. and A. Krewani (eds.), Media and Mapping Practices in the Middle East and North Africa:Producing Space. Amsterdam: Amsterdam University Press, 2021 DOI 10.5117/9789462989092_CHo8 
This chapter focuses exclusively on the body-space relationship invoked by the practice of parkour in a local setting, as well as on the body-space relationship inherent in its visual representation. This focal point has been selected to link the two aforementioned discourses: the first about the engagement of the body with the public space, and the second about the relevance of parkour in digital media. The aim is also to shed light more generally on the fundamental tension between the practice itself, on the one hand, and its visualization, on the other. In the wake of the iconic/pictorial turn (Boehm 2001; Mitchell 2008; Alloa 2015) and the resulting culture of enhanced visuality, images are more easily created and distributed due to the digital transformation of the technology needed. Consequently, a renewed focus on the structure of the visual material and its relation to the depicted practices seems to be of particular importance.

Parkour is practised across the world, including in the Middle East and North Africa (MENA) region. I approach parkour from a Moroccan perspective, which does not mean that I am a Moroccan traceuse; I am a female German researcher taking the ideas and positions imparted to me by Moroccan traceurs during my field research (2012-2014), and using these as a lens through which the body-space dynamic of a particular global cultural practice can be observed. This chapter will address the following questions: What characterizes the body-space relationship and the spatial knowledge of the local discourse and the practice of parkour on the local ground? How is the body-space relationship visualized? How are these two approaches related, and what are the implications for (and beyond) the body-space relationship?

To answer these questions, this chapter is structured as follows: after a short introduction to parkour, the next section deals with its underlying theoretical assumptions with respect to the body and sensory ethnography. This is followed by an investigation into the body-space relationship during the practice of parkour, which will then be confronted with the body-space relationship inherent in visual and digital records of parkour (this section begins with a commentary on media and visual ethnography). Finally, this chapter offers an analysis of three parkour images from a Moroccan traceur, and some concluding thoughts.

\section{Parkour as a Global and as a Moroccan Cultural Practice}

The idea behind parkour is to find the most direct path between two points and to overcome any obstacle within that path, using only one's own physical and mental capacities (Belle 2009; Lauschke 2010; Angel 2011; Thibault 2013). 
Although nothing other than one's own body is needed to practise parkour, it is mainly trained and organized in groups. Male parkour actors are called traceurs, while female actors are called traceuses, to indicate that these actors trace their way through their environment. Any barriers or hindrances on the route are perceived as a challenge, and will be integrated into the parkour movements, without in any way affecting or damaging them.

Alongside the street practice, part of the cultural practice of parkour is also the production of visual material, in the form of photos, videos, or other media. Indeed, street and media practices are interrelated constituent components of parkour, which itself is a circular process. The circulation between the performances on the street and those in the video clips is constituted through citation, repetition, and modification. Internet applications provide the virtual architecture for the media performances - that is, free platforms on which to post the clips and the possibility of easily circulating and commenting on them - while benches, buildings, and bridges provide the material architecture for the street performance.

Since its inception in the 1980 s and 1990 in the suburbs of Paris, parkour - or the art of displacement (l'art du déplacement) - reached the wider public via media representations: parkour became internationally popular through films and documentaries with and about its founding figures, David Belle and Sébastien Foucan. ${ }^{1}$ For many traceurs, their initial encounter with parkour occurred through films and, later, video clips on YouTube. Furthermore, music videos, commercials, and computer games began to copy and include parkour moves and, in doing so, increased parkour's international visibility and popularity.

In the early 2000s, parkour groups started to emerge in places as diverse as France, the United Kingdom, the United States, Mexico, Russia, Spain, and Japan. The story of parkour in Morocco can be traced back to the years 2005-2006, when young teenagers saw their first parkour moves in the French films Yamakasi (2001) by Ariel Zeitoun and Banlieue 13 (2004) by Pierre Morel, interestingly both co-authored by Luc Besson. ${ }^{2}$ They were attracted by these

1 David Belle is said to be the founding figure of parkour. He was born in 1973 in Fécamp (France), where his father, who trained as a soldier in Vietnam, taught him escape moves. Belle translated these movements into the concrete setting of cities. Sébastien Foucan was one of the first traceurs associated with Belle, who later followed his own ideas and founded free running. Free running accentuates the acrobatic, rather than the most efficient, mode of displacement. I am aware of these differences, which are also discussed in the community, but they are irrelevant for the purpose of this chapter. When I talk about parkour here, free running is included.

2 In the following part, I try to trace the history of parkour in Morocco based on interviews I conducted with different pioneers of the parkour community in the country, such as Soufian and Badr from MpK in Marrakech, and Adil from Accroches Toi in Casablanca. Both groups are considered the first parkour practitioners in Morocco. In addition to this, I refer to an interview 
moves and were inspired to translate them into their own environment, so they began to train alone or with a handful of friends in their neighbourhoods. While searching for additional information and material about parkour on the internet, the groups came into contact with each other. These personal encounters were crucial for the further development of parkour in Morocco. Added impetus was provided by visits from international traceurs, such as a Belgian Moroccan traceur who was also in contact with David Belle, and who shared his experience during training sessions with traceurs in Morocco. As soon as Moroccan traceurs established a certain level of proficiency, they started to take pictures of their best movements, and those who had access to the technical equipment tried to produce footage for videos.

Due to the availability of technical equipment and the ongoing spread of digitization since the 200os, digital media practices became integral to the cultural practice of parkour, alongside the global emergence of local groups. Today, Moroccan traceurs, as well as global parkour communities, organize themselves and communicate via different social media channels (mainly Facebook, YouTube, and Instagram).

Today, hundreds of traceurs are active all over Morocco. ${ }^{3}$ A number of groups and individuals are active in metropolitan areas such as Casablanca, Marrakesh, and Tangier, but parkour is also practised by young people far from such urban centres - in Berkane and in the surroundings of Agadir, for example. Parkour is performed on the roofs of public schools, municipal buildings, or mosques in the city; on top of private houses in residential areas; in empty villas, on crowded beaches, and even at famous architectural sites. With respect to their corporeal skills, as well to their visual, technical, and digital engagement, traceurs are involved at different levels. They train as individual traceurs, but they have also established parkour groups, many of which have been active for several years, and are involved in global parkour institutions, such as Ibkano in Casablanca or Jlafet in Tangier. The different local actors are well connected via social media but also personally; they visit each other and undertake shared training sessions in different Moroccan cities.

Moroccan parkour practitioners have produced themselves. In it, Ahmad Bakkali, a brother of the founding member Badr of MpK, tells the story of parkour in Morocco: Ahmed Bakkali's Interview - PARKOUR, https://www.youtube.com/watch?v=fbgTk_v6KGs (last accessed 18 November 2020). 3 The following description about the present-day Moroccan parkour community is the result of field research and participant observation in Morocco since 2012. In addition to this, I conducted qualitative interviews with around 30 traceurs and 3 traceuses, mainly in 2014 during field research, but also in the following years, up to today. In the course of the chapter, I refer to the interviews I conducted. 
The fact that Moroccan parkour actors originate from a diverse range of social backgrounds rather contradicts the common assumption that global cultural trends are mainly the preserve of middle-class adolescents. Nothing other than one's own body is required to practise parkour, which opens up opportunities for participation, irrespective of the financial resources at one's disposal. In interviews, traceurs often mention that, through parkour, they have encountered people from different social backgrounds, and that they have established close ties with them.

Like other body-centred sport cultures (surfing, skateboarding, climbing, etc.), parkour is rather male dominated. ${ }^{4}$ Nonetheless, it is also practised by some women, including in Morocco and other Arab countries. However, traceuses in Arab countries are confronted by a gamut of prejudices towards the idea of women moving expressively through public space. ${ }^{5}$

\section{The Body and Sensory Ethnography}

The body, in my approach, is a regulated but conscious and sensory entity. In recent decades, the body and its practices have become increasingly prominent in social theory through concepts such as Bourdieu's 'habitus' (1977), Butler's 'gender performativity' (1988; 1990), Foucault's 'biopolitics' (1976), and Howes' 'sensing culture' (2003). Within the hyper-rationalist

4 There is a scientific debate about the role of gender in sport cultures, which also questions hegemonic white masculinities in it. See e.g. Robinson 2008 with a focus on climbing, Thorpe 2008 for snowboarding, Yochim 2009 for skateboarding, Kidder 2013 for parkour, and the important volume Women in Action Sport Cultures: Identity, Politics, and Experience (2016), edited by Holly Thorpe and Rebecca Olive, which includes many inspiring articles and interviews with pioneers in this field. For parkour in this edited volume, see Wheaton 2016. See also the volume entitled New Sporting Femininities: Embodied Politics in Postfeminist Times (2018), edited by Toffoleti et al.

5 There is sparse literature about women and gender in sport cultures in 'non-Western' settings. Wheaton writes in her article about gender and parkour: 'These insights remind us to look outside of our predominantly white Western perspectives and empirical contexts to map the differences in gender and its intersectionality with ethnicity and religion, as well as other markers of identity to expose the complex and contradictory articulations of identity in these informal but increasingly globally widespread spaces and settings in which action sports takes place' (2016, p. 130). However, here are some references for parkour: Braune (2019) on gender and parkour in the Arab World, and Thorpe and Ahmad (2015) about parkour in Gaza. There is also a quite vibrant female parkour community in Iran; you can find some journalistic snapshots about it here: 'Fast-paced parkour offers outlet for women in Iran', 2014: http://www. nydailynews.com/life-style/health/iranian-women-embrace-parkour-article-1.1731975 (last accessed 18 November 2020), and Fazekas 2018. 
and hyper-intellectualized context of social theory, notions of the 'body', 'things', and 'practical knowledge' have become increasingly relevant as well (Reckwitz 2002, p. 258). A focus on practices implies centring on agency, rather than an exclusive reliance on texts, discourses, and mental processes. Reckwitz draws on the work of Bourdieu, Foucault, Latour, and Butler to describe practices as a set of 'routinized bodily performances' and 'mental activities' (2002, p. 251). Focusing on practices means 'the exploration of the embeddedness of the mental activities of understanding and knowing in a complex of doings' (Reckwitz 2002, p. 258).

In this vein, my main interest lies in the reconstruction of how parkour ' is produced by a nexus of [...] practices as body/knowledge/things-complexes' (Reckwitz 2002, p. 258). A post-structuralist approach is taken here, in that space is presented as something that is materialized through bodily practices. As de Certeau puts it:

[I] it is true that a spatial order organizes an ensemble of possibilities (e.g. by a place in which one can move) and interdictions (e.g. by a wall that prevents one from going further), then the walker actualizes some of these possibilities. In that way, he makes them exist as well as emerge. But he also moves them about and he invents others, since the crossing, drifting away, or improvisation of walking privilege, trans-form or abandon spatial elements. (1988, p. 98)

At the moment of the parkour encounter, the identity of the architectural site is questioned. The traceur not only confirms a distinctive architectural structure but also contests its identity. Buildings and places are perceived with alternate perspectives. For example, a windowsill is explored as a potential foothold to overcome a certain distance. This allows the sill to continue to function as intended, and at the same time, its function is changed: 'in doing so the traceur not only changes his own perception of the building but also changes the building itself as perceived object' (Fuggle 2008, p. 215).

To put the spotlight on the body allows for an incorporation of the sensorial dimension, in the sense that there is no separation between the corporeal experience and the rational mind: 'the experiencing, knowing and emplaced body is therefore central to the idea of a sensory ethnography' (Pink 2015, p. 28). Concisely, a sensory ethnography includes the senses in the process through which knowledge is produced and takes into account knowledge which is not spoken. Three topics are central in the debate on the anthropology of the senses: the relationship between senses and culture, vision and its relation to other senses, and 'reflexivity that goes beyond the 
interrogation of how culture is "written" to examine the sites of embodied knowing' (Pink 2015, p. 13).

Sensory ethnography takes its impulses from different disciplines such as anthropology, human geography, and sociology. Due to this chapter's focus on space, I refer to works from geography and walking studies (Wunderlich 2008; Edensor 2010; Middleton 2010; Yi'En 2013), especially with regard to practising parkour in a local setting. The reference to walking studies is made due to a basic commonality between walking and parkour - namely, that only the body, bereft of any additional instruments, moves through and shapes space. The geographer Yi-Fu Tuan has consistently argued that, to achieve a more complex understanding of objects, places, and their relation, the senses must be taken into account (Tuan 1977). In Sensuous Geographies (1994), Paul Rodaway proposes an approach that 'offer[s] a more integrated view of the role of the senses in geographical understanding: the sense both as a relationship to a world and the senses as themselves a kind of structuring of space and defining of place' (1994, p. 4). When moving, it is not only the feet but rather the whole body that is involved and in contact with the environment. Rodaway classifies four different ways of 'getting in touch' with the environment: the 'global touch' 'represents the body's general contact with the environment' and refers to the feeling and reaffirmation of one's own body in a certain spatial context. The 'reach touch' denotes the contact of feet and fingers, for example, with the environment. Here, the feeling of the texture comes into play. The 'extended touch' is mediated through an instrument or device, while the fourth 'imagined touch' is based on tactile memory and/or expectations (Rodaway 1994, p. 48).

In her article 'Walking and Rhythmicity: Sensing Urban Space', Wunderlich explores three modes of walking and highlights implications for urban design. Irrespective of whether the form of walking is characterized as 'purposive', 'discursive', or 'conceptual', the basic rhythmicity of walking remains inherent to it: 'the rhythm of walking is influenced by the interaction with other external rhythmical events that we came across in urban environments, such as other walking practices, or other bodily movements or activities that contrast in pace or rhythm' (Wunderlich 2008, p. 133). ${ }^{6}$ In the case of walking, it seems that '[a] notion of place is acquired through the participatory attribute of the haptic sense' (Wunderlich 2008, p. 129), which relates to the conditions of the pavement (e.g. cobblestone, flagstones, gravel) (Gehl 1987), as well as to the responsiveness (Endensor 2010) and the

6 About rhythmicity, see also Edensor 2010; about different kinds of walking, see also Middleton 2010 . 
affectiveness of materialities (Yi'En 2013). Edensor includes mechanisms that regulate the style of walking, from outside weather conditions to the form of clothing (2010, p. 73). He refers to Lefebvre's notion of 'dressage' 'as a means to train the body to perform and condition it to accede to particular rhythms so that people walk "properly", do not slouch, put their shoulders back and firmly plant their heels down first' (Edensor 2010, p. 71). Middleton extends this argument to the embodiment of places (2010).

In addition to the rhythmicity and purpose of walking, the quality of surfaces, weather conditions, clothing, and the learned way of walking, there are also normative expectations which are deeply embedded in society with regard to gender-appropriate behaviour and the given architectural structures that regulate the sensory body and its movement.

\section{Sensing Parkour while Practising It}

A key component of the cultural practice of parkour is seeing the environment with parkour-eyes; the perception of one's own surroundings starts to change significantly. The priority then becomes to look for good spots to perform new manoeuvres. In what follows, I refer to this as the 'parkour gaze'. On both an intentional and unintentional level, this crucial and comprehensive change of perception structures the practitioner's movements through the city. The traceur either consciously searches for a good spot, or is en route to somewhere else, such as school or work, and coincidentally discovers a suitable setting. The parkour gaze has an explicit interest in discovering potentially interesting athletic challenges, with the attention lying primarily on the surfaces of a given structure (place or object). What happens inside a building, the historical background of a certain structure or area, is not important to the successful performance of parkour-related movements.

My argument here is that this perception represents a radical perspective on public space, because it disregards the putative symbolic meaning, social status, or historical prestige of buildings, places, or objects (see also Atkinsons 'urban deconstruction' with regard to parkour, 2009). Furthermore, it is worth highlighting that the perception of public space is primarily driven by the potential athletic challenges offered by a certain architectural structure. Different architectural structures assume importance depending on one's corporeal capability and the intended parkour manoeuvres. A wall's height or inclination for climbing over or for leaping off; the distance between benches for jumping over or from one to another; the presence of a handrail to offer balance - such features now assume a special significance. 
Once the traceur has arrived at a (new) spot, the surfaces and dimensions of the location are carefully measured through a close sensory investigation. The information that is useful for practising is to be found on the surface itself, rendering a detailed and deep knowledge of it indispensable. The surface's character is experienced through close tactile contact - through touching, pushing, and scratching. By tangibly touching it, the traceur acquires the necessary information with respect to stability, firmness, and grip, for example. Furthermore, distances and conditions are evaluated through careful examination, while the smell provides further information about the place. Does it smell of fragrant flowers or of rotting rubbish? The odour offers evidence about context and situatedness, as well as about the weather. The same is true for the taste - during intensive training sessions, dust as well as sweat and water are tasted (differently).

While all of this is occurring, the traceur also hears noises which the body produces during the practice of parkour: the squeak of sneakers over different surfaces, the rush of wind while flipping in the air, the heavy breathing while performing a particularly demanding sequence of motions. Furthermore, it may be possible to hear the comments of observers, as well as a range of other background noises, as parkour sessions transpire against the soundscapes of public space, whether in the centre of a metropolitan city, at the beach, or in a lower-class residential area. For some traceurs, this sonic dimension is an important component of parkour and is by no means perceived as annoying, whereas others prefer to listen to music while training. This serves different purposes: 'During the training we can listen to music that inspires us, to make our level better and to make us feel free. It also helps us not to feel bored from training' (personal interview, 16 October 2013, Facebook).

Depending on the information collected through tasting, hearing, seeing, smelling, and palpation, the traceurs start to test aspects of their planned movements before proceeding to perform complex motion sequences. The appropriation of a new location, as well as regular play sessions, are characterized by a high level of repetition. The same motions are continuously repeated ten times, a hundred times, a thousand times. A fundamental aspect of parkour is precisely this repetition, which has two interrelated meanings: first, to exercise intensively and repetitively in preparation for a move or figure, and second, to ensure that the skill is successfully completed if the figure can be repeated again and again.

Through this process of continuous repetition, the specific location becomes embodied, in a very literal sense of the word. This embodiment is intensively related to the location insofar as it is not readily reproducible at another place with different spatial and surface conditions. Furthermore, while practising 
parkour, the traceur comes into bodily contact with urban materials such as dust, mud, and rubbish, inhales car exhaust gases, smells a baker's shop, hears people chatting, and gets dirty. The places inscribe themselves even deeper into the body; sometimes the body is marked by small scratches, bloody wounds, or even serious injuries. In addition, of course, the body is profoundly shaped through repetitive training, not only to perform a specific place-related move but more generally with regard to its overall constitution.

Not only the body but also the place is physically shaped by direct contact. I argued above that a given building or location changes its character and function when it is perceived as an object for the parkour encounter. In terms of the more or less visible tracks left through wear and tear, this also holds true for the physical encounter. Moreover, traceurs also restructure particular settings to suit their purposes.

The relation between body and space is characterized by a close sensorial connectedness and an embodied perception of places and their spatial relations. The body is in direct contact with the space; it gets dirty, it inhales, it touches and tastes the dust and the earth. Moreover, like the place, the body is shaped by the encounter through repetitive exercises. At the same time, the places become embodied (both inwardly and outwardly) through repetitive training, as well as through small scratches and wounds.

A deep and detailed knowledge of the structures and qualities of surfaces is acquired through tactile and haptic contact, as well as through a visual, sonic, smelled, and tasted perception of it. As the parkourian body forges paths that were not originally made for walking and jumping, the sensorial encounter provides vital information for a creative and secure performance. I argue here that it is through the very practice of parkour that spatial elements acquire new and different meanings. The body-space relation imparts this meaning in the very moment of encounter. Parkour implies new ways in which space is negotiated and appropriated that were not originally intended by city planners and architects. Parkour-related practices thus implicitly contest traditional forms of behaviour, as well as the intended functions of particular public spaces.

\section{Media and Visual Ethnography}

The visual material and its digital circulation are part of parkour and open it up to a wider audience. Approaching parkour through its media practices and products allows for varying levels of involvement. In what follows, I will briefly touch on several perspectives, which conceptualize parkour as 
a media practice, thereby linking it to other sport (media) cultures (such as skateboarding, snowboarding, windsurfing, and climbing). These practices all have an important visual component and are characterized by a special and fundamental relationship between cultural practices and evolving media technologies. In recent research, such practices and sports have been variously described as 'life style sports' (Gilchrist and Wheaton 2013), Stil-Kulturen (translated as 'style cultures', Stern 2010), or as 'action sport cultures' (Thorpe and Olive 2016), and also as 'new', 'extreme', 'alternative', or 'freestyle' sports. For the purpose of this chapter, I use the term 'cultural practice' to refer to the broader cultural context and practices in which these athletic activities are embedded.

Early subcultural studies addressed media coverage, and specifically the extent to which media coverage could constitute a 'co-opting' of the subversive potential of style-orientated cultural practices (Hebdige 1979). Scholars writing in the 1990 s tended to arrive at a very different conclusion, however; namely, that different cultural communities 'use specialist or "niche" media for their own purposes - not merely to disseminate information, but also to establish (and to regulate) collective identity' (Buckingham 1999; Thornton 1995).

As in the cases of surfing (Booth 1996; 2001), skateboarding (Borden 2001; Buckingham 2009), and other sports, media has played and continues to play a crucial role in the development of parkour, on many different levels (Gilchrist and Wheaton 2013; Kidder 2012; Ladewig 2008). The history of each of these cultural practices is very much linked to medial production because through films and documentaries, these practices have become internationally visible and popular. In more recent years, parkour's international visibility and popularity have been further enhanced by YouTube, music videos, commercials, and computer games, attracting young people all over the world to imitate parkour movements and adapt them to their own surroundings. Furthermore, different parkour communities are mainly (self-) organized, on both a local and global level, through particular social media channels. Gilchrist and Wheaton highlight the importance of 'continuities with pre-Internet forms of communication' (2013, p. 170), and here I would further emphasize the role of 'internet-supplementary' forms of communication. Overall, however, Facebook, YouTube, and Instagram provide the digital architecture for parkour media practices and performance. The opportunity to participate - that is, the availability of online forums on which to post information, pictures, and videos free of charge, and the possibility of easily circulating and commenting on these clips both locally and globally - constitute structures of marginalization and exclusion. 
With respect to the visual material produced by parkour practitioners and taking into account the power of representation - the story of parkour might be told as a narrative produced firstly through Western documentaries and representations about it, until, secondly, more self-presentation by the practitioners - as expressed through their own self-made videos - became prevalent. As the technology needed to take photographs and record footage becomes cheaper and more available in Morocco, Moroccan traceurs are able to produce and spread their own visual representations. Due to their creativity and professionalism, the Moroccan traceurs are able to produce digital representations of themselves.

The value of the visual material is constantly being negotiated within the different lifestyle communities in terms of what is perceived as a 'good' picture or a 'nice' video. This is shaped by, and dependent upon, the development of filming technology and equipment. The media practices of parkour range from simple unedited photos to animated pictures, HD videos recorded with smartphones, digital reflex cameras, action cameras (such as GoPro), or camera drones. These different technologies, as well as the editing software used and perspectives chosen, are central to the pictures and videos that are ultimately produced. This also touches on sensitive questions around access to technology, and especially the highly professionalized knowledge needed to manipulate it, to produce what is perceived as a 'good video'.

In the following, I will make explicit how I work with visual material as a means of knowledge production. The engagement with visual material hints at the tense relationship between visual and perceived reality, between sight and the other senses, and between the visual and textual, as the result of academic knowledge production.

I approach visual material in several different ways. As a matter of principle, this chapter deals solely with photos, even though videos are equally important components of parkour's media culture. This focus on photos has profound implications on the sensorial encounter of the body-space relationship, because pictures rely exclusively on the visual sense (whereas videos, for example, also have a sonic component). There is a close relationship between image and video in the sense that the images are themselves usually extracted from video footage, with images effectively snipped from a movement to capture the motion more expressively.

Firstly, I use photos I have personally taken to underline the sensorial description of the spots. Even though these relate exclusively to the visual dimension, they are employed here to provide a more vivid illustration of the spatial relations of the chosen sites. Furthermore, my photos were taken without any specific technology; in other words, I used a simple camera without 
any specific angle or filter. I am nonetheless aware that these photos are not realistic renderings of a given place, but merely constructed moments of reality.

Secondly, I work with photos taken and produced by a Moroccan traceur to analyse the body-space relationship and its fundamental constructedness in and through the visual material. The production of parkour images is critically reliant on a profound knowledge of the movement sequences in parkour, on the ability to anticipate and accompany the movements, and on the handling and manipulation of the advanced recording technology and editing software. Furthermore, knowledge of what is perceived within the parkour community as a good and thrilling image is vital. Traceurs often told me that collaboration with otherwise talented and well-equipped cinematographers who did not have a parkour background failed because they lacked this important knowledge of parkour movements and their visual representation.

To elaborate on my argument, and to highlight the specificity of the spatial knowledge in parkour images, I contrast the sensorial description of the chosen spots with the photos I have taken, which offer some idea of the general spatial setting of the edited images of one Moroccan traceur taken at the same spot.

Therefore, out of hundreds of different spots in Marrakech, I have chosen three exemplary images, due mainly to their diversity but also to their popularity. These images are from Abderrahim Arradi, a traceur from Marrakech, who has been practising parkour since 2006 and has developed a remarkable physical proficiency. Abderrahim Arradi puts a great amount of energy into the visual representation of his talents, which has gained him widespread recognition, not just locally but also globally.

\section{A Sensorial Description of the Spots}

The following sensorial descriptions of the spots encompass the sensorial encounter of parkour while practising in different public spaces, thus offering a more intimate insight into three specific settings.

$\mathrm{Al}$ Anber is the name of an urban quarter where several traceurs live, including Abderrahim Arradi. Al Anber can be considered as the residential courtyard of the city's lower class. This spot is very important to the traceurs, and it is used intensively as an everyday training ground (Figure 8.1). It is soundtracked by the daily hustle and bustle of the surrounding flats and the public spaces: mothers shouting for their children to come for dinner, music, televisions, the smell of cooked food. Inhabitants usually pass through the courtyard, and children play there (and, indeed, receive their first 


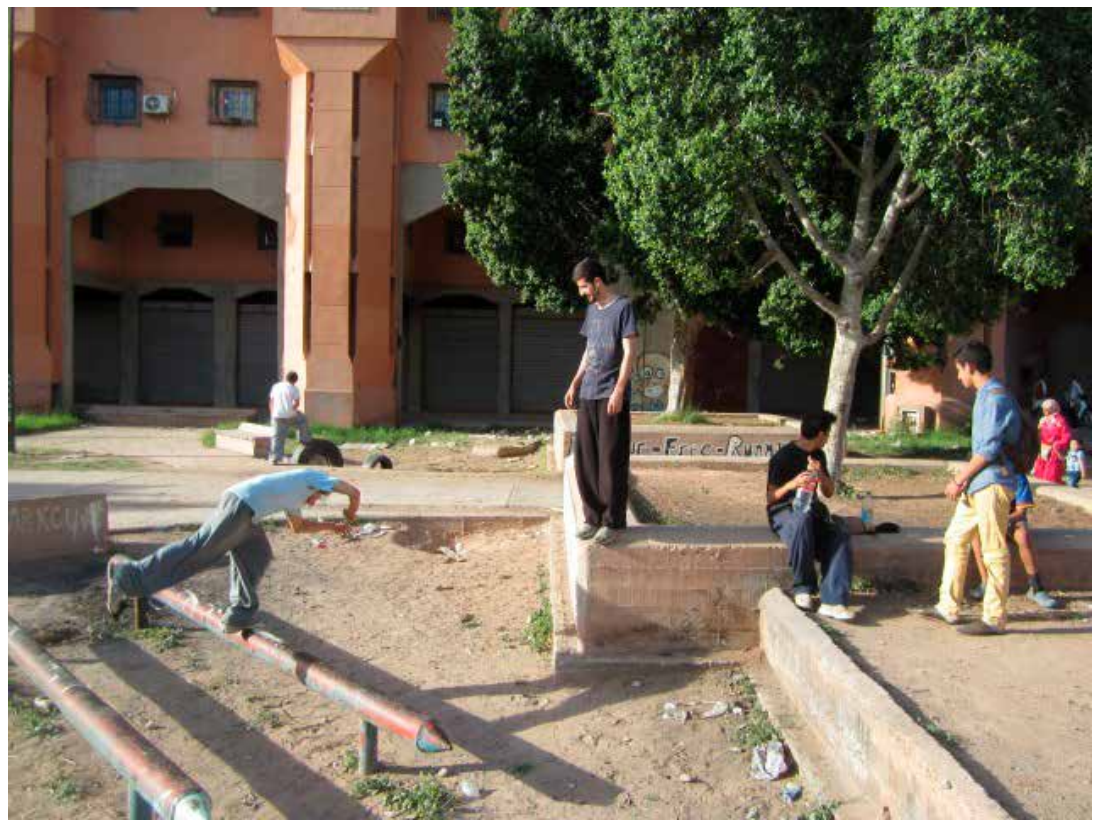

Figure 8.1: Al Anber. Photo: Ines Braune.

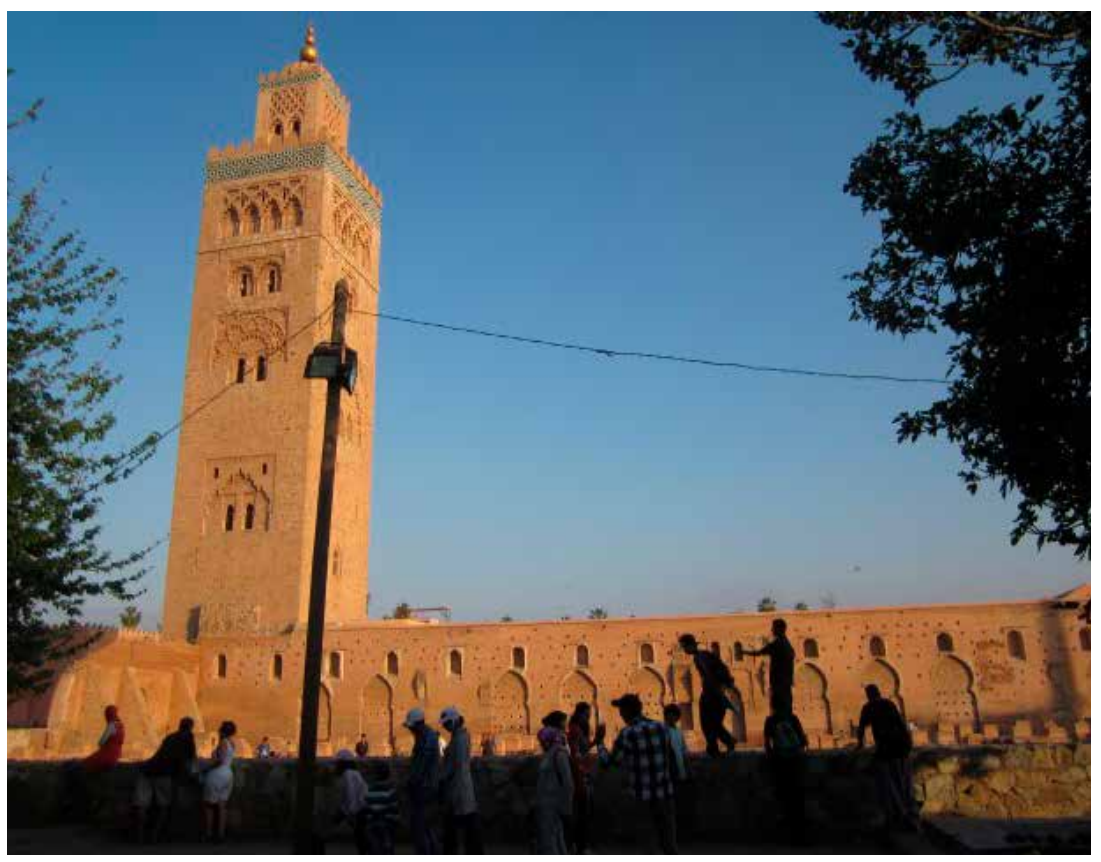

Figure 8.2: Koutoubia Mosque in Marrakech. Photo: Ines Braune. 


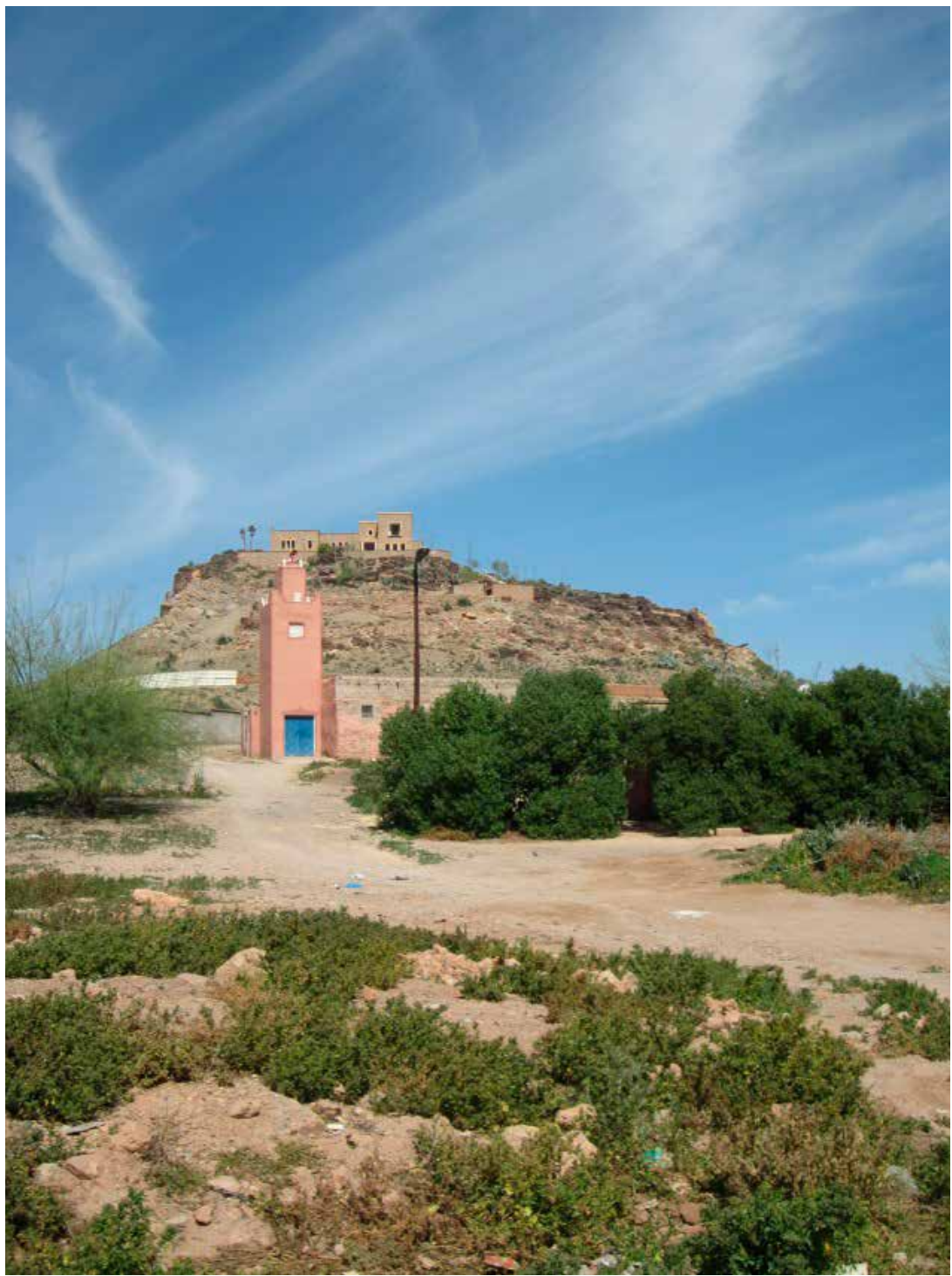

Figure 8.3: 'The castle'. Photo: Ines Braune.

parkour lessons). Nearly every single given structure in the courtyard is perceived as a potential training surface: the branches of trees are used to swing on, the iron bars at the forefront of the picture are used to train one's balance, the different distances and heights between walls are used to jump on, off, or over. The traceurs also tend the spot and try to keep it clean, while periodically rearranging it for their own special purposes, such 
as by putting an old tyre in the sand to use as a springboard, while an old mattress functions as an exercise mat for secure landings.

The second spot is the famous Koutoubia Mosque in Marrakech (Figure 8.2). It is one of the most well-known and important tourist attractions in the heart of the city. It lies opposite the Jamaa El Fna, is surrounded by a network of busy central roads, and is frequented by inhabitants of Marrakech as well as by local and international tourists. The parkour sessions here take place in a quite astounding setting, amidst the vivid soundscape of a city centre alive with the noise of traffic and crowds, of passers-by and astonished spectators. The athletic challenges at this spot lie in the minaret, different-sized bases of columns, and various handrails.

The next spot is a building located on the outskirts of Marrakech known to the traceurs as 'the castle' (Figure 8.3). This is an unfinished empty villa on a hill with an amazing view over Marrakech that extends to the snow-capped Atlas Mountains. Its outer façade is complete but devoid of window glass, while the interior of the multilevel villa comprises a set of incomplete stairs and only a preliminary, foundational distribution of rooms. These structures have proven inspiring, setting the scene for several extraordinary parkour recordings. The castle is a semi-public place, in the sense that it is not on any public transport link. In addition, the whole area is sealed off by a wall at the foot of the hill. The place was discovered by one of the traceurs while working nearby as a painter. However, traceurs are not the only lords of this castle; they share it with other refuge-seekers (such as the homeless or drug addicts). Because it is far from the city, the air here is filled with a certain freshness, but it also offers a glimpse into the abysses of human existence.

\section{Visual Analysis of the Body-Space Relation in the Images}

\section{Al Anber}

In the first picture, taken in the courtyard at $\mathrm{Al}$ Anber, we see a human body elevated in midair in the middle of the image (Figure 8.4). The bottom third is taken up by a panoramic view of Al Anber's courtyard, while the upper two-thirds are filled with blue sky and wispy clouds. It seems to be a backlit photograph: dark, with only few gradations. Details are hardly recognizable, and it is not clear whether the person depicted is male or female. The picture is characterized by a tension between the flat body and the increased spatiality of the architecture through the curved horizon. 


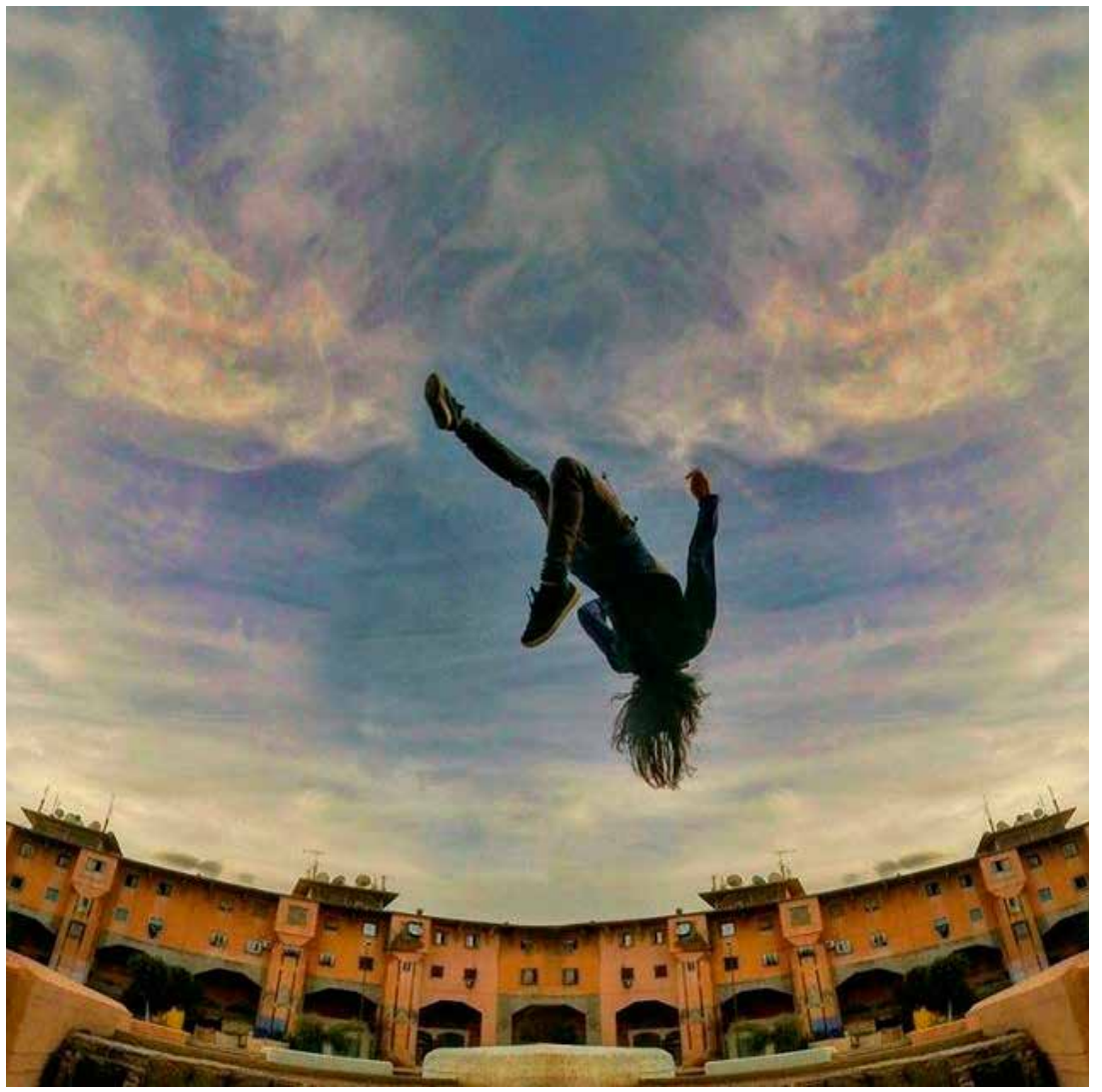

Figure 8.4: 'Superman'. Photo: Abderrahim Arradi.

While the body is mainly black, the colours of the background are edited and form a complementary contrast between blue and orange (against the coloured background, the dark figure does not really fit into the image, or even appears detached from it). With the help of the 'hero' or 'superman' perspective (i.e. from below), the body appears frozen in the sky, with seemingly no relation to the architecture or the ground, like a flying bird that contradicts human limitations and gravity.

\section{Koutoubia}

This picture shows the famous mosque Koutoubia in the city centre of Marrakech (Figure 8.5). In the middle of the picture, the traceur bridges a divide in a wall. The leaping body is in focus, and even the face is recognizable. As in figure 8.4, the body appears entirely framed by the sky, and the photo is also taken from the 'hero' perspective, from below. In the bottom half of 


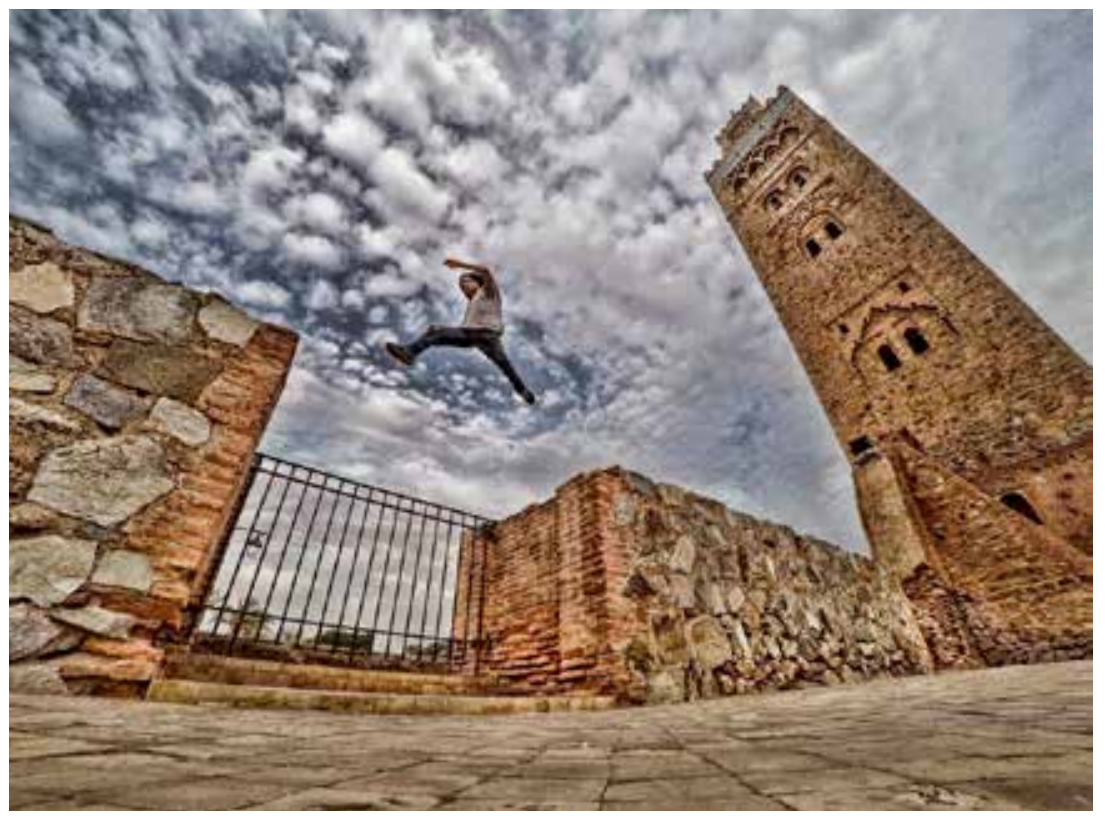

Figure 8.5: 'Jump'. Photo: Abderrahim Arradi.

the picture, we see a panorama of the paved floor, parts of the wall, and the minaret of the former mosque. The upper half of the picture is filled with cloudy sky. This picture has been reworked and the contrasts sharpened; consequently, the structure of the pavement, as well as the stone wall and the minaret, are extremely clear. The same is true of the cloudy sky. The spatiality is highlighted through the curved horizon. Against this backdrop, the body seems to be frozen and serves as a point of tranquillity. In contrast to the other pictures, the standpoint of the observer is obvious, as is the landing point of the traceur. The photographer and the observer stand on the pavement and most probably recognize the sequence of the movement, the starting and landing points. Furthermore, the body is more integrated into the picture and serves as a kind of connection across the divide in the architectural structure.

While in the other two pictures the tension is created through the unexpected, the intensely motionable body and its exclusion, in this picture the body seems to recognize the impossibility of remaining suspended in the air, and connects to the manmade architecture.

\section{The Castle}

The picture is divided into two parts (Figure 8.6). On the left-hand side of the foreground, there are close, finely structured parts of an unfinished, 


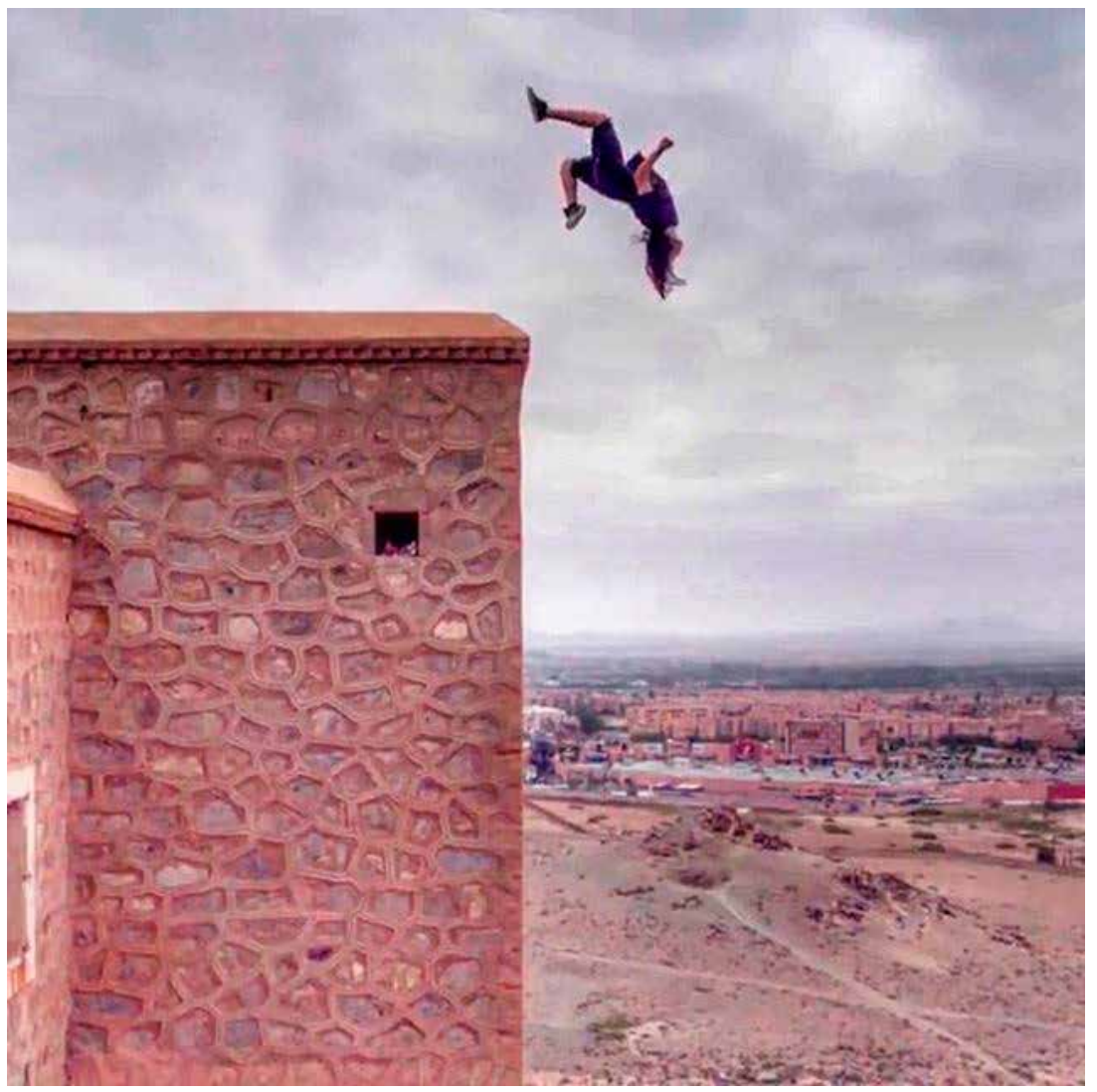

Figure 8.6: 'Flying body'. Photo: Abderrahim Arradi.

flat-roofed, multilevel villa. On the right-hand side, the observer has an extensive view and can see, firstly, the incline on which the villa was built, followed by the (typically Marrakechian) red-coloured sea of houses, with the horizon composed of the spectacular snow-capped Atlas Mountains. In the upper part of the picture is a rotating human body, which, as in the other two pictures, is surrounded completely by sky. In contrast to the other two pictures, however, this has not been taken from the 'hero-perspective' - in other words, not from below. Instead, the camera is located at the same height as the screened body. Due to the architectural structure of the building, this was only possible with a drone camera, which was used to produce a video clip. The photo was extracted from the video footage and subsequently edited; the colours and their contrasts were sharpened, and the photo was mirrored.

Against the flat, monotonous sky, the 'flying body' is striking, also due to its (constructed) posture, the angled arms, offset legs, curved upper body, and falling hair. The tension in this picture is created through the spatial 
arrangement, the sharp contrast between extreme movement and stillness, and through the uncertain moment of contact with the ground.

With regard to the description of the image content in all three pictures, the body is surrounded by sky and has no contact at all with the architectural structures of the particular setting. The images convey the impression of a body detached from the places and from the natural law of gravitation; they seem to fly or hover above their surroundings. The frozen body in the sky conveys a certain separateness from the banality of the grounded everyday: lightness and freedom versus seriousness and problems. Nevertheless, the architectural structures of the places serve as crucial points of reference for the situatedness and proficiency of the body.

The construction of this surface of the image content is quite complex. The viewer looks at what is not actually shown, what remains invisible, and thus at the techniques of construction. All signs of physical exertion are invisible; sweat-distorted faces due to the complicated and challenging moves are hidden from view. There is no indication of the direct encounter with the surfaces, no dirt, and no dust. Furthermore, there is no contextual information about the places, or about how the video was recorded, or about how long the practitioner has trained to perform such impressive moves. The qualities of the buildings' surfaces are similarly unrecognizable.

With respect to the construction of the image, the chosen perspective plays an important role. Two of the three pictures are taken with the 'hero' or 'superman' perspective from below, which makes the body appear larger. The third picture was taken at eye level by a drone camera, but because of the specific site of the recording (the most elevated point in the location), as well as of the splitting of the image, the body is also elevated above everything else.

Furthermore, complicated graphic filters are applied to the digital image to highlight, and neglect, particular information. In all three pictures, the colours as well as the contrasts are edited. In the first two pictures, the image horizons are curved, which creates a stronger sense of spatiality of the architectural structures.

Perspective, the splitting and arrangement of the image, and different graphic filters are all important tools for producing parkour images that simultaneously reflect weightlessness, tension, and risk.

\section{Concluding Remarks on the Sensorial, the Visual, and the Textual}

Street practices require an intense knowledge about and a dense sensorial contact with the surfaces of the architectural structures of the public space. 
The body exerts itself, it transpires; it is exhausted, and it is satisfied. The body has a close haptic relation to the places and feels it; the body carefully measures, maps, and evaluates the surfaces through its eyes; the body smells, tastes, listens, sees, and feels the spatial surroundings. By doing so, the body reaffirms and recreates spatial relations. The body is involved as subject and actor of the movements and is manipulated through intense training sessions to perform the movements. Simultaneously, the body is shaped by the places and in a literal sense, the places are embodied as well, and the places are shaped by the encounter. Furthermore, the regular street practices are characterized by a high level of repetition, control, and safety. The body as a tool to practise will not be risked easily or recklessly.

In contrast to this, the visualization of the body-space relation in parkour reflects a contrary approach. The images by their very nature refer exclusively to the visual sense. With regard to the body-space relation, there is no direct contact between the body and the surfaces depicted. The images are edited in a way to visualize a distance between the body and the different architectural structures, even though the different places are crucial references to give meaning to the body-space relation. Moments of exertion and strain are not visible and the body becomes a flying object (instead of actively producing the moves). The detached body as object is technically manipulated by camera settings, angles, and the editing process. Repetition, control, and safety are replaced in the pictures by extraordinary singularity, risk, and danger.

Both approaches - the body-space relation while practising parkour on the streets and the body-space relation in the visual material - seem to be driven by antagonistic momentums: connectedness versus detachedness, the routine versus the extraordinary, subject versus object, and control versus risk. Both approaches follow different ideas and construct the relationship between body and space in a distinct way. This hints at the crucial claim about the limitedness of assertions about practices while looking exclusively at the visual material and vice versa.

Working with the visual material opens up a broader access to embodied knowledge but underlines a certain predominance of the visual sense, which excludes further frames of sensorial knowledge. Furthermore, the academic knowledge production is based on textuality, meaning the knowledge gained has to be translated into a written text.

I argued in the beginning of this chapter that the exploration of the bodyspace relationship as practice and as representation are used to relate the two to each other. They constitute components of parkour but also of other media-intense lifestyle and sport practices, though the approaches to how 
body and space are related are diverse and sometimes even contradictory. Parkour can be and is practised without any recording technology, but when visual material of one's own practices is targeted, the recording becomes part of the training session. Furthermore, the images, which are edited and technically manipulated for extraordinary moments, are mainly taken during routinized training sessions and settings. The body-space relationship while practising parkour is mediated through the production of visual material in various ways. The places of the routinized training sessions are reimagined through the images as results of the visual material. Moreover, the digital recordings of the movements are evaluated directly after performing the movements on the screens of the cameras. Here again, the body-space relation is perceived through the visual material with an aesthetic but also athletic claim. The direct evaluation of the material is done through an analysis of the aesthetic composition; in other words, how to improve and accentuate certain body parts or how to improve the athletic performance. The digital recording technology enables the traceurs to slice their movements into the tiniest parts (invisible to the eye while performing) to improve, control, and shape their body knowledge. Referring to Rodaway's classification of getting in touch with the environment, the 'global touch' of parkour is intensively shaped by the parkour gaze, a gaze on the places that signals aesthetic as well as athletic challenges but disregards any historical or reputational meaning. 'Reach touch' describes the sensorial encounter of body and place with all senses. The 'extended touch' is mainly mediated through the recording technology, while the 'imagined touch' refers to memory as well as the power of imagination of the different moves performed or to be performed at a place.

\section{References}

Ahmed Bakkali's Interview - PARKOUR, Online Resource: https://www.youtube. com/watch?v=fb9Tk_v6KGs (accessed 18 November 2020).

Emmanuel Alloa, 'Iconic Turn. A Plea for Three Turns of the Screw', Theory, Culture \& Critique, 53(3) (2015).

Julie Angel, Ciné Parkour (self-published, 2011).

Michael Atkinson, 'Parkour, Anarcho-Environmentalism, and Poiesis', Journal of Sport and Social Issues, 33 (2009), pp. 169-194.

David Belle, Parkour (Paris: Intervista, 2009).

Ines Braune (2019), 'Gender and Parkour in the Arab World', in Building Bodies: Transnational Historical Approaches to Sport, Gender and Ethnicities, Yearbook of Women's History, ed. by Saskia Bultman, pp. 193-207. 
Gottfried Boehm, ed., Was ist ein Bild? (Munich: Fink, 2001).

Douglas Booth, 'Surfing Films and Videos. Adolescent Fun, Alternative Lifestyle, Adventure and Industry', Journal of Sport History, 22 (1996), pp. 313-327.

-,Australian Beach Cultures. The History of Sand, Sun and Surf (London: Frank Cass, 2001).

Iain Borden, Skateboarding, Space and the City: Architecture and the Body (Berg: Oxford, 2001).

Pierre Bourdieu, Der Tote packt den Lebenden (Hamburg: VSA Verlag, 1997).

-, Outline of a Theory of Practice (Cambridge: Cambridge University Press, 1977).

David Buckingham, 'Skate Perception: Self-Representation, Identity and Visual Style in a Youth Subculture', in Video Cultures. Media Technology and Everyday Creativity, ed. by David Buckingham and Rebekah Willet (Basingstoke: Palgrave Macmillan, 2009), pp. 133-151.

Video Cultures, Media Technology and Everyday Creativity, ed. by David Buckingham and Rebekah Willet (Basingstoke: Palgrave Macmillan, 2009).

Judith Butler, 'Performative Acts and Gender Constitution: An Essay in Phenomenology and Feminist Theory', Theatre Journal, 40 (1988), pp. 519-531.

-, Gender Trouble. Feminism and the Subversion of Identity (New York: Routledge, 1990).

Michel de Certeau, Michel, The Practice of Everyday Life (Berkeley: University of California Press, 1988).

Tim Edensor, 'Walking in Rhythms: Place, Regulation, Style and the Flow of Experience', Visual Studies, 25 (2010), pp. 69-79.

Agnes Fazekas, 'Fatimeh fliegt', Brigitte, 2 (2018), pp. 44-48.

Michel Foucault, The Will to Knowledge: The History of Sexuality, 1, trans. by R. Hurley (1976) (London: Penguin, 1998).

Sophie Fuggle, 'Discourses of Subversion: The Ethics and Aestethics of Capoeira and Parkour', Dance Research, 26 (2008), pp. 204-222.

Jan Gehl, Life Between Buildings. Using Public Space (New York: Reinhold, 1987).

Paul Gilchrist and Belinda Wheaton, 'New Media Technologies in Lifestyle Sports', in Digital Media Sport: Technology and Power in the Network Society, ed. by Brett Hutchins and David Rowe (Florence Routledge, 2013), pp. 169-185.

Dick Hebdige, Subculture: The Meaning of Style (London: Methuen, 1979).

David Howes, Sensing Culture: Engaging the Senses in Culture and Social Theory (Ann Arbor: The University of Michigan Press, 2003).

Emily Chivers Yochim, Skate Life: Re-Imagining White Masculinity (Ann Arbor: University of Michigan Press, 2009).

Jeffrey L. Kidder, 'Parkour, The Affective Appropriation of Urban Space, and the Real/Virtual Dialectic', City \& Community, 2 (2012), pp. 229-253.

-,'Parkour, Masculinity, and the City', Sociology of Sport Journal, 30 (2013), pp. 1-23. 
Rebecca Ladewig, 'Play It, But Seriously. Zur medialen Inszenierung von Le Parkour', Montage AV. Zeitschrift für Theorie und Geschichte audiovisueller Kommunikation, 17 (2008), pp. 109-130.

Jennie Middleton, 'Sense and the City: Exploring the Embodied Geographies of Urban Walking', Social \& Cultural Geography, 11 (2010), pp. 575-596.

William John Thomas Mitchell, Bildtheorie (Frankfurt: Suhrkamp, 2008).

Sarah Pink, Doing Visual Ethnography (Los Angeles: Sage, 2013).

-,Doing Sensory Ethnography (Los Angeles: Sage, 2015).

Paul Rodaway, Sensuous Geographies: Bodies, Sense and Place (London: Routledge, 1994).

Andreas Reckwitz, 'Toward a Theory of Social Practices. A Development in Culturalist Theorising', European Journal of Social Theory, 5 (2002), pp. 245-265.

Victoria Robinson, Everyday Masculinities and Extreme Sport. Male Identity and Rock Climbing (Oxford and New York: Berg, 2008).

Martin Stern, Stil-Kulturen. Performative Konstellationen von Technik, Spiel und Risiko in neuen Sportpraktiken (Bielefeld: transcript, 2010).

Vincent Thibault, Parkour and the Art du déplacement. Strength, Dignity, Community (Montréal: Baraka Books, 2013).

Yi-Fu Tuan, Space and Place: The Perspective of Experience (Minneapolis: University of Minnesota Press, 1977).

Holly Thorpe and Nida Ahmad, 'Youth, Action Sports and Political Agency in the Middle East: Lessons from a Grassroots Parkour Group in Gaza', International Review for the Sociology of Sport, $5^{0}$ (2015), pp. 678-704.

Holly Thorpe and Rebecca Olive, ed., Women in Action Sport Cultures. Identity, Politics and Experience (London: Palgrave, 2016).

Holly Thorpe, 'Foucault, Technologies of Self, and the Media: Discourses of Femininity in Snowboarding Culture', Journal of Sport and Social Issues, 32 (2008), pp. 199-229.

Kim Toffoletti, Jessica Francomb-Webb, and Holly Thorpe, ed., New Sporting Femininities. Embodied Politics in Postfeminist Times (London: Palgrave, 2018). John Urry, 'The City Life and the Senses', in A Companion to the City, ed. by Gary Bridge and Sophie Watson (Chichester: Wiley-Blackwell, 2012), pp. 388-397.

Belinda Wheaton, 'Parkour, Gendered Power and the Politics of Identity', in Women in Action Sport Cultures. Identity, Politics and Experience, ed. by Holly Thorpe and Rebecca Olive (London: Palgrave, 2016), pp. 111-132.

Mato Filipa Wunderlich, 'Walking and Rhythmicity: Sensing Urban Space', Journal of Urban Design, 13 (2008), pp. 125-139.

Cheng Yi'En, 'Telling Stories of the City: Walking Ethnography, Affective Materialities, and Mobile Encounters', Space and Culture (2013), pp. 1-13. 


\section{About the Author}

Ines Braune has a background in Middle Eastern and media studies and has been researching culture and media changes from a cultural studies perspective. Her research interests include youth, inequalities, and cultural practices in the Middle East. Having focused on everyday internet practices of young Moroccans, her $\mathrm{PhD}$ dissertation dealt with local appropriations of globally available resources. Her current research is on parkour as a mediatized cultural practice in the Arab world. She was co-editor of the open access METAJournal-Middle East Topics and Arguments and is currently the managing director of the Marburg University Research Academy (MARA). 
